\title{
Genetic testing for cancer predisposition: need and demand
}

Human cancers may follow exposure to particular environmental factors, but it is well established that cancer is, at the cellular level, genetic in origin. Mutations associated with initiation and progression are usually acquired "somatic" events. However, occasionally one of these genetic changes may be inherited, or the cell is less capable of repairing DNA, resulting in a predisposition to cancer. Familial clustering of common cancers presents perhaps one of the biggest dilemmas for health economists. While most cancers are not susceptible to any accepted form of screening, three of the sites most commonly involved include breast, ${ }^{1}$ bowel, ${ }^{2}$ and ovary. ${ }^{3}$ While screening for these cancers is not fully accepted, most cancer genetics clinics would offer screening to those at high risk. There is also the prospect of preventive surgery for some who choose this option. The last year has seen major advances with the cloning of the breast/ovarian susceptibility gene BRCA $1,{ }^{4}$ and four genes predisposing to bowel and other cancers. ${ }^{5-7} \mathrm{Up}$ until this year it has only been possible to offer a linkage diagnosis in very few kindreds with breast and ovarian cancer with sufficient evidence of linkage to BRCA1 to make heterogeneity very unlikely. ${ }^{8}$ There are perhaps only 20 such families in the UK, which does not present a major problem. Even with the localisation of the hereditary non-polyposis colon cancer (HNPCC) genes, ${ }^{5-7}$ presymptomatic linkage diagnosis will only be possible in very few extra families. This is because none of the genes contributes more than $50 \%$ of $\mathrm{HNPCC}^{910}$ and there is as yet no tumour phenotype which distinguishes one from another. However, the ability to detect mutations in even a small proportion of those with hereditary predisposition in the newly cloned genes will have major implications.

At present the vast majority of work in the cancer predisposition field, including molecular genetic analysis and cancer genetics clinics, is research funded. There is no immediate prospect, at least in the UK, of a major injection of government money to cope with the inevitable increase in demand. So who should be offered tests and how should these be done? Even the most enthusiastic population screener would find it difficult to advocate offering a BRCA1 mutation test to all people who requested one. This would require a massive expansion of laboratory services as well as an impossible burden on clinical services if any peri-test counselling were to be offered. A more realistic approach might be to offer a test to those with a family history of breast or ovarian cancer. However, as 1 in 12 women develop breast cancer in their lifetime in the UK many women will have some degree of family history by chance alone. Even if one restricted access to those with a more significant history there would potentially be a huge demand. What will a positive or negative screen mean for someone? Those in the general population without a family history would have less than $0 \cdot 1 \%$ chance of carrying a mutation in BRCAl. Therefore a negative (normal) screen would not reduce their risks of breast cancer even if the screen were $100 \%$ sensitive. Those with a first degree relative with breast cancer at 45 years of age, having a 1 in 6 lifetime risk, would not receive any real reduction in their probability of developing the disease. Even those with a strong family history of breast and ovarian cancer and a $90 \%$ sensitivity for mutation testing would not have sufficient risk reduction to cease other regular screening or preventive measures (DF Easton, personal communication). It seems logical therefore only to offer a predictive test when a mutation has been identified in a family and has been shown to be disease causing. This will allow reassurance for those who have not inherited the family mutation and allow informed risk estimates of breast and ovarian cancer for those with the mutation. Even the latter may be difficult in a small nuclear family where it would be difficult to assess whether the mutation conferred a high $(85 \%)$ or low $(30 \%)$ risk of ovarian cancer. ${ }^{11}$

In the main part, research laboratories will be testing those families or affected people with a high probability of BRCA1 mutation. This could be because the family is linked to BRCA1, has many cases of breast/ovarian cancer, or that a person has developed either disease at a young age or has a double primary. Once a mutation has been found this will usually be passed on to a service laboratory for verification and to allow a test to be offered to the extended family. However, research money will be temporary and provision now needs to be made for the initial mutations to be identified in the service laboratories.
Early indications are that around $60 \%$ of women offered a BRCA1 test will take up the option. This comes from our own preliminary data from 75 people in five families as well as from a population survey and a clinic survey. ${ }^{12}$ If new techniques, such as protein truncation testing (PTT), identify a high proportion of BRCA1 mutations (and early evidence suggests they will), there would need to be a considerable increase in the number of genetic counsellors and clinicians able to prepare at risk subjects sufficiently for a predictive test. Given that mutations are now being identified in the HNPCC genes, and the BRCA2 gene ${ }^{13}$ may soon be cloned, there will have to be a major injection of public money or a radical change in the attitude of the funding bodies if genetic services will actually be able to offer a test, or indeed to cope with the consequences of being able to do so.

D GARETH EvaNS

Department of Medical Genetics, Christie Hospital, Manchester M20 9BX, and St Mary's Hospital, Manchester M13 OfH, UK

1 Newman B, Austin MA, Lee M, King M. Inheritance of human breast cancer: evidence for autosomal dominant transmission in high-ris 8.

2 Lynch HT, Lanspa SJ, Bonan BM, Smyth T, Watson P, Lynch JF. Hereditary non-polyposis coloGastrenterol Clin North Am 1988;174:679-715.

3 Schildkraut JM, Thompson WD. Familial ovarian cancer: a population-based case-control study. cancer: a population-based case-co

4 Miki Y, Swensen J, Shattuck-Eidens D, et al. A strong candidate for the breast and ovarian cancer gene BRCA1. Science 1994;266:66-71.

5 Leach FS, Nicolaides NC, Papadopoulos N, et al. Mutation of a mut $S$ homolog in hereditary non polyposis colorectal cancer. Cell 1993;75:121525.

6 Papadopoulos N, Nicolaides NC, Wei Y-F, et al. Mutation of a Mut L homolog in hereditary colon cancer. Science 1994;263:1625-9.

7 Nicolaides NC, Papadopoulos N, Liu B, et al. Mutation of two PMS homologs in hereditary non-polyposis colorectal cancer. Nature 1994; 371:75-80.

8 Easton DF, Ford D, Bishop DT. Breast and ovarian cancer incidence in BRCA1 mutation ovarian cancer incidence in BRCA

9 Nystrom-Lati M, Parson R, Sistonen P, et al. Mismatch repair genes on chromosomes $2 p$ and $3 p$ account for the major share of hereditary nonpolyposis colon cancer families evaluable by linkage. Am f Hum Genet 1994;55:659-65.

10 Froggatt NJ, Koch J, Davies R, et al. Genetic linkage analysis in hereditary non-polyposis colon cancer syndrome. f Med Genet (in press).

11 Easton DF, Bishop DT, Ford D, Crockford GP, and the Breast Cancer Linkage Consortium Genetic linkage analysis in familial breast and ovarian cancer: results from 214 families. $A m \mathcal{F}$ Hum Genet 1993;52:678-701.

12 Mohammed S, Barnes C, Watts S, Michie S, Hodgson $S$. Attitudes to predictive testing for BRCA1. F Med Genet 1995;32:140A.

13 Wooster R, Neuhausen SL, Mangion J. Localization of a breast cancer susceptibility gene, BRCA2, to chromosome 13q12-13. Science 1994;266:2088-90. 